\title{
Surgical strategies for the treatment of os odontoideum with atlantoaxial dislocation
}

\author{
Xinghuo Wu, MD, ${ }^{1}$ Kirkham B. Wood, MD, ${ }^{2}$ Yong Gao, MD, ${ }^{1}$ Shuai Li, MD, ${ }^{1}$ Jing Wang, MD, ${ }^{1}$ \\ Ting Ge, MD, ${ }^{1}$ Boming Zhao, MD, ${ }^{1}$ Zengwu Shao, MD, ${ }^{1}$ Shuhua Yang, MD, ${ }^{1}$ and Cao Yang, MD'
}

\begin{abstract}
1Department of Orthopaedics, Union Hospital, Tongji Medical College, Huazhong University of Science and Technology, Wuhan, China; and 'Department of Orthopaedic Surgery, Massachusetts General Hospital and Harvard Medical School, Boston, Massachusetts
\end{abstract}

OBJECTIVE This study aimed to compare the clinical results of using posterior fixation and fusion with or without anterior decompression to treat os odontoideum with atlantoaxial dislocation.

METHODS Twenty-five consecutive patients with os odontoideum were included in this study. Sixteen patients with reducible atlantoaxial dislocation were treated by single-level posterior fusion and stabilization; the other 9 were treated with posterior fusion and stabilization combined with transoral decompression. Pre- and postoperative CT scans and MR images were obtained.

RESULTS Twenty-four patients were followed for 24-54 months (average 36.5 months). Postoperative CT scans indicated that all pedicle screws were placed satisfactorily except in 2 cases, in which the screws slightly penetrated the transverse foramen. Postoperative MR images demonstrated that sufficient decompression of the spinal cord was obtained in all patients. Complications included 1 case each of pedicle screw breakage, pharynx ulcer, and persistent pharynx discomfort. Statistical analysis of all cases revealed that mean Japanese Orthopaedic Association scores improved from a preoperative score of 10.2 (range 7-13) to a postoperative score of 15.6 (range 11-18).

CONCLUSIONS Patients who have os odontoideum with a reducible atlantoaxial dislocation can be effectively treated with single-level posterior fusion and stabilization. Combined transoral decompression and posterior fusion and stabilization is recommended for those with irreducible atlantoaxial dislocation.

https://thejns.org/doi/abs/10.3171/2017.5.SPINE161211

KEY WORDS os odontoideum; atlantoaxial dislocation; transoral decompression; posterior fusion; cervical

$\mathrm{O}$ $\mathrm{S}$ odontoideum is a rare cervical anomaly, which was first described in the late 1880s; however, its treatment strategy remains controversial. Surgeons have varying opinions regarding the treatment of asymptomatic os odontoideum, although it is widely accepted that the condition may lead to atlantoaxial instability. The etiology of os odontoideum remains under discussion, and it is unclear whether it is of congenital or traumatic origin. ${ }^{4}$ Some patients may be asymptomatic, but when they are young, neck pain, torticollis, or neurological symptoms can occur after repeated spinal cord injury or vertebral artery (VA) compromise. ${ }^{6,11}$ If patients with os odontoideum do not have symptoms or C1-2 instability, they can be managed with regular clinical and radiographic inspection.
Patients with symptomatic atlantoaxial instability and dislocation have been advised to consider operations such as spinal cord decompression and solid internal fixation and fusion for long-term stabilization. ${ }^{2,26}$ However, it is impossible to obtain a good clinical result by a single-level posterior approach in patients with irreducible atlantoaxial dislocation. For reducible subluxation of $\mathrm{C} 1-2$, a singlelevel posterior bone fusion and fixation procedure is suitable, but in cases of irreducible subluxation of $\mathrm{C} 1-2$, the procedure is not optimal. As reported in the literature, posterior decompression and stabilization and an additional transoral decompression were thought to be appropriate for treatment of os odontoideum with irreducible atlantoaxial dislocation. ${ }^{20,22}$ A transoral atlantoaxial reduction plate fixation could be applied in patients with os

ABBREVIATIONS JOA = Japanese Orthopaedic Association; VA = vertebral artery; VAS = visual analog scale.

SUBMITTED October 9, 2016. ACCEPTED May 22, 2017.

INCLUDE WHEN CITING Published online November 17, 2017; DOI: 10.3171/2017.5.SPINE161211. 
odontoideum and irreducible atlantoaxial dislocation, but it is often accompanied by complications such as wound infection, CSF leakage, neurological injury, and hardware loosening. $3,27,31$

In the current study, we treated patients with os odontoideum by posterior pedicle screw fixation and fusion with or without anterior transoral decompression on the basis of whether it reduced the dislocated atlantoaxial joint. Postprocedure clinical outcomes were followed and evaluated for the 2 surgical regimens.

\section{Methods \\ Clinical Data}

Between October 2011 and April 2014, 25 patients with symptomatic os odontoideum with atlantoaxial dislocation were treated surgically in our department. There were 17 male and 8 female patients, ranging in age from 12 to 47 years (average 30.5 years). All patients presented with neck pain and restriction of neck movement, as well as clinical signs of myelopathy, with the duration of symptoms ranging from 1 to 5 years. The clinical signs and symptoms were measured by Japanese Orthopaedic Association (JOA) score.

\section{Radiographic Evaluation}

Preoperative radiographic evaluation included anteroposterior and lateral cervical radiographs, flexion and extension lateral radiographs, CT scans with sagittal and coronal reconstructions, and MR images. Dynamic radiographs demonstrated instability of the atlantoaxial joint. CT scans were used to assess anatomical landmarks, as well as length and direction of the pedicles and vascular anatomy, especially for the presence or absence of an anomalous VA. MR images were obtained to assess ventral compression of the spinal cord on the basis of high signal intensity in T2-weighted images of the $\mathrm{Cl}-2$ region.

\section{Preoperative Skull Traction}

Preoperative skull traction is very important for atlantoaxial joint instability and subluxation, which could determine the surgical method to be used based on the regularly obtained bedside radiograph plain films. All patients underwent skull traction (4-10 kg for 1-2 weeks) preoperatively. The patient and family members were informed regarding the importance of preoperative traction and the possible associated complications. During the process, bedside radiographs were obtained to evaluate the reduction of $\mathrm{C} 1-2$ joints, avoiding hypertraction and incidence of accidents. Sixteen patients (64\%) had a reducible subluxation of $\mathrm{Cl}-2$; the other 9 patients (36\%) did not have reduction of the dislocated os odontoideum.

\section{Surgical Techniques}

Surgical strategies for the treatment of os odontoideum are based on reduction. Patients with reducible atlantoaxial dislocation were treated by posterior fusion and stabilization with 4-10 kg of traction. Patients with irreducible atlantoaxial dislocation were treated with combined trans- oral decompression and posterior fusion and stabilization, with the assistance of skull traction. In addition, some patients for whom reduction could be obtained with the assistance of skull traction still displayed cord compression due to residual hyperplasia of ligaments and scar tissue; these patients underwent a combined anterior and posterior operation.

\section{Transoral Decompression}

Initially, the patient was placed supine. The transoral approach was performed with the assistance of adjustable retractor support, which could expand the mouth and depress the tongue, exposing the posterior wall of the pharynx. A vertical incision was made on the posterior pharyngeal wall, from the anterior tubercle of $\mathrm{C}-1$ to the vertebral body of $\mathrm{C}-2$. Then, the mucous membrane of the pharynx posterior wall, pharyngeal constrictor, pharynx buccal fascia, vertebral muscles, and anterior longitudinal ligament attached to the anterior arch of $\mathrm{C}-1$ and the vertebral body of C-2 were cut and retracted. With the assistance of a high-speed power drill, the anterior arch of the atlas was gradually worn off to a width of approximately $2.0 \mathrm{~cm}$. Then, the fat or fibrous connective tissues were removed, and the odontoid process was finally worn off too. If there was ligament calcification under the odontoid process, it was also removed to achieve thorough decompression. After strictly controlling the bleeding, the mucous membrane and muscularis of the pharynx posterior wall were sutured.

\section{Posterior Fusion and Stabilization}

In this study, a reducible os odontoideum was approached posteriorly only, whereas an unreducible subluxation with spinal cord compression was operated on by anterior decompression combined with a dorsal route for posterior fusion and stabilization. Briefly, after the induction of general anesthesia, the patient was placed prone with persistent skull traction. Then, a standard posterior midline incision of the occiput-3 junction was made, with clival exposure between the occipital condyles and the bodies of C-3. Posterior instrumentation and fusion at only the C1-2 level was performed in 21 patients, whereas C1-3-level fixation and fusion was performed in 2 patients with anomalous VA, and occipitocervical fusion was performed in 2 patients with occipitocervical instability after transoral anterior decompression. For the latter 2 patients, the distances from the anterior margin of the foramen magnum to the posterior arch of the atlas, and from the posterior margin of the foramen magnum to the anterior arch of the atlas, were measured on the basis of radiological data. According to the Powers measurement standards, a ratio $>1$ and occipitocervical instability were indicated. Under C-arm radiograph monitoring, reduction of the atlantoaxial joint was achieved using the assistance of skull traction, with the head positioned as flexed as possible. Following reduction and fixation, a U-shaped autologous iliac crest graft was placed between the posterior arches of $\mathrm{C}-1$ and $\mathrm{C}-2$, and 1-0 absorbable sutures were used to fasten the structural autograft between the precontoured rods on both sides. 



FIG. 1. A 17-year-old boy presented with os odontoideum with reducible atlantoaxial dislocation. Lateral (A) and anteroposterior (B) cervical radiographs, a CT scan (C), and a sagittal MR image (D) show a typical os odontoideum presentation. Intraoperative photographs show that the patient underwent placement of bilateral C-1 lateral mass screws and C-2 pedicle screws (E) and an iliac crest autograft between $\mathbf{C}-1$ and $\mathbf{C}-2(\mathbf{F})$. Postoperative anteroposterior $(\mathbf{G})$ and lateral $(\mathbf{H})$ radiographs show $\mathbf{C} 1-2$ instrumentation and complete reduction of the atlantoaxial joint. A postoperative MR image (I) demonstrates sufficient decompression of the spinal cord. Figure is available in color online only.

\section{Postoperative Evaluation}

Neck circumference is routinely used during a 3-month evaluation postoperatively. Radiographs, CT scans, and MR images were obtained within the 2nd postoperative week and at 1 month, 3 months, and 6 months after surgery to assess the reduction of the $\mathrm{C} 1-2$ subluxation and the decompression of the spinal canal during follow-up.

\section{Statistical Analysis}

Preoperative and postoperative changes in JOA scores were tested using the paired t-test. All data are presented as the mean \pm standard error of the mean. All analyses were performed with Prism 5 (GraphPad). Statistical differences were considered significant for $\mathrm{p}$ values $<0.05$.

\section{Results}

Anterior dislocation was observed in 15 patients (60\%), posterior dislocation in 3 patients (12\%), and both anterior and posterior dislocation in 7 patients (28\%). CT scans showed an anomalous VA in 2 patients. Preoperative symptoms were neck pain and myelopathy at presentation, caused by os odontoideum with atlantoaxial dislocation. Surgery was indicated for patients who presented with os odontoideum and a reducible atlantoaxial dislocation, who were treated by single-level posterior approaches with bone fusion and stabilization (Figs. 1 and 2); those with an irreducible dislocation were treated with combined transoral decompression and posterior fusion and stabilization (Fig. 3).

The mean follow-up duration was 36.5 months (range 24-54 months). One patient treated by combined transoral decompression and posterior fusion and stabilization was lost to follow-up. Among the 24 patients with adequate clinical follow-up, according to the visual analog scale (VAS) scores of the patients, all experienced significant pain relief or improvement of functional ability, demonstrating $>87.9 \%$ improvement in VAS scores $(\mathrm{p}<0.01)$. Among the 12 patients with myelopathy preoperatively, 8 had complete resolution of their neurological symptoms, 3 had improvement in their spasticity, and 1 ultimately presented with unchanged spasticity. Statistical analysis of data in all 24 patients revealed a mean JOA score of 10.2 (range 7-13) before surgery and 15.6 (range 11-18) at the 


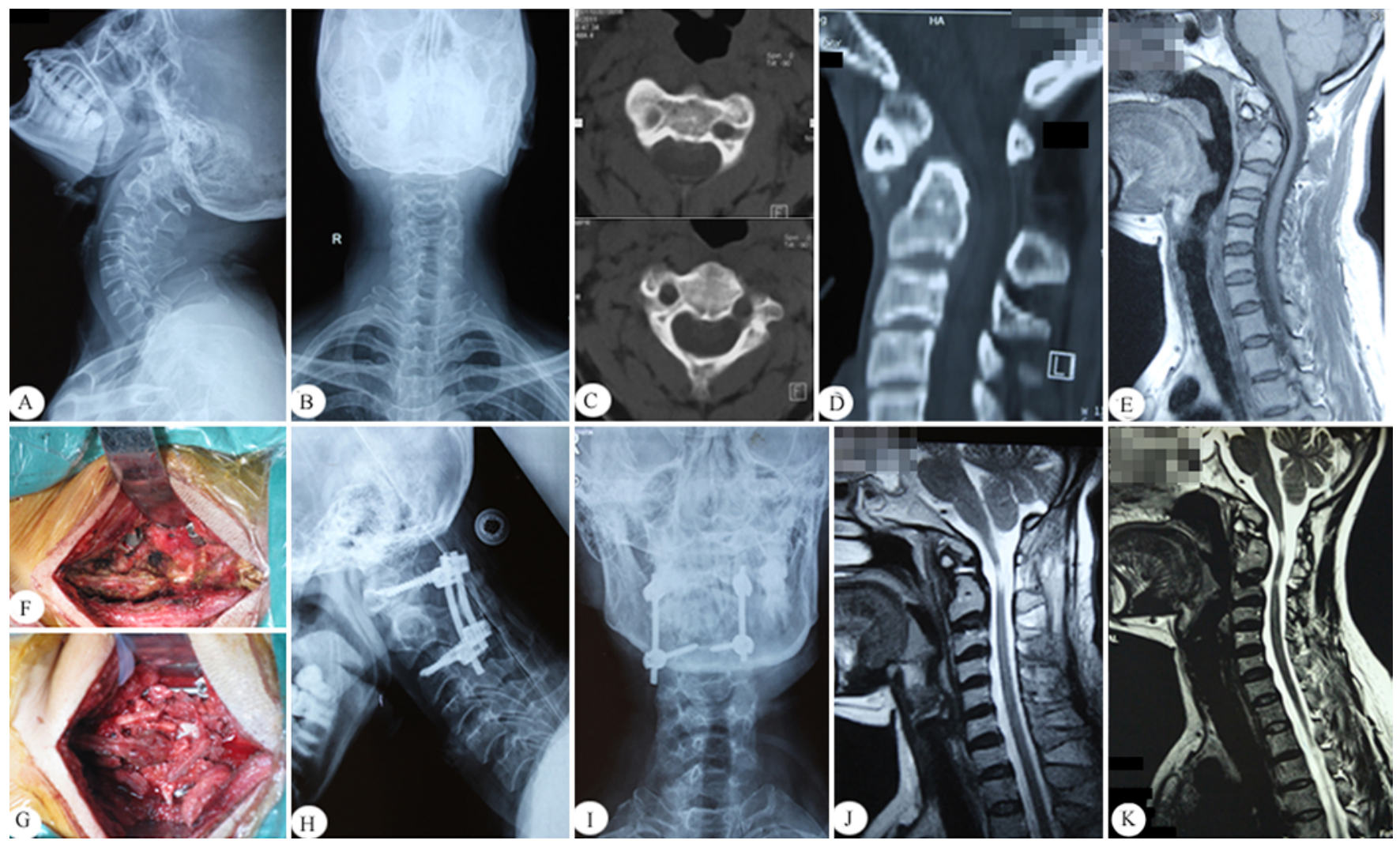

FIG. 2. A 42-year-old woman presented with os odontoideum with atlantoaxial dislocation. Lateral (A) and anteroposterior (B) cervical radiographs show a typical case of os odontoideum. CT scans (C) show an anomalous VA. A CT scan (D) shows an irregular ossicle at the tip of the odontoid process with atlantoaxial dislocation. An MR image (E) shows ventral compression of the cervical spinal cord. Intraoperative pictures show that the patient underwent placement of bilateral C-1 lateral mass screws and C-3 pedicle screws $(\mathbf{F})$ and an iliac crest autograft $(\mathbf{G})$. Postoperative radiographs ( $\mathbf{H}$, lateral; $\mathbf{I}$, anteroposterior) show $\mathrm{C} 1-3$ instrumentation. A postoperative MR image $(\mathbf{J})$ demonstrates sufficient decompression of the spinal cord. An MR image $(\mathbf{K})$ obtained at the 1.5-year follow-up shows complete restoration of the spinal cord. Figure is available in color online only.

final follow-up. The difference between the preoperative and the final JOA scores was statistically significant $(\mathrm{p}<$ $0.01)$.

Postoperative MR images demonstrated sufficient decompression of the spinal cord in all patients, and fusion was achieved in all patients at a median of 6.5 months (range 3-15 months). Postoperative CT scans indicated that all pedicle screws were placed satisfactorily, except in 2 cases in which the screws slightly penetrated the transverse foramen. However, in this case series, there were no VA injuries during surgery and no subsequent development of any neurological complications. Complications included 1 case each of breakage of the pedicle screws, development of a pharynx ulcer, and persistent pharynx discomfort. The patient with breakage of the pedicle screws was treated with revision fusion, after which the patient had no neurological deficits, and solid fusion of the cervical spine was obtained (Fig. 4). Cervical spinal fusion was assessed on the basis of posterior CT data. All patients had bony fusion (100\% fusion rate) at final follow-up, at an average of 6 months (range 3-12 months).

\section{Discussion}

We have presented a series of patients with os odon- toideum and C1-2 instability to evaluate the outcomes of their management. Based on our clinical practice, regular and effective skull traction was applied, and the atlantoaxial joint was able to be realigned by traction. Excellent clinical results and high fusion rates were achieved in these patients, including significantly better improvement in VAS and JOA scores and a $100 \%$ fusion rate at the final follow-up.

When treating os odontoideum with atlantoaxial dislocation by surgery, we conclude that if improvements in alignment and reduction are achieved, then the position can be maintained by skull traction and simple posterior stabilization, and fusion can then be performed. Otherwise, transoral decompression combined with posterior fusion and stabilization are suggested. Those patients with os odontoideum who do not show evidence of atlantoaxial instability or neurological symptoms, however, should be strongly considered for regular examination on the basis of radiographs and clinical interviews, with avoidance of all contact sports.

It is obvious that a symptomatic patient who suffers from os odontoideum, with or without radiographic evidence, should undergo surgery. However, arguments continue regarding how to treat asymptomatic patients without 


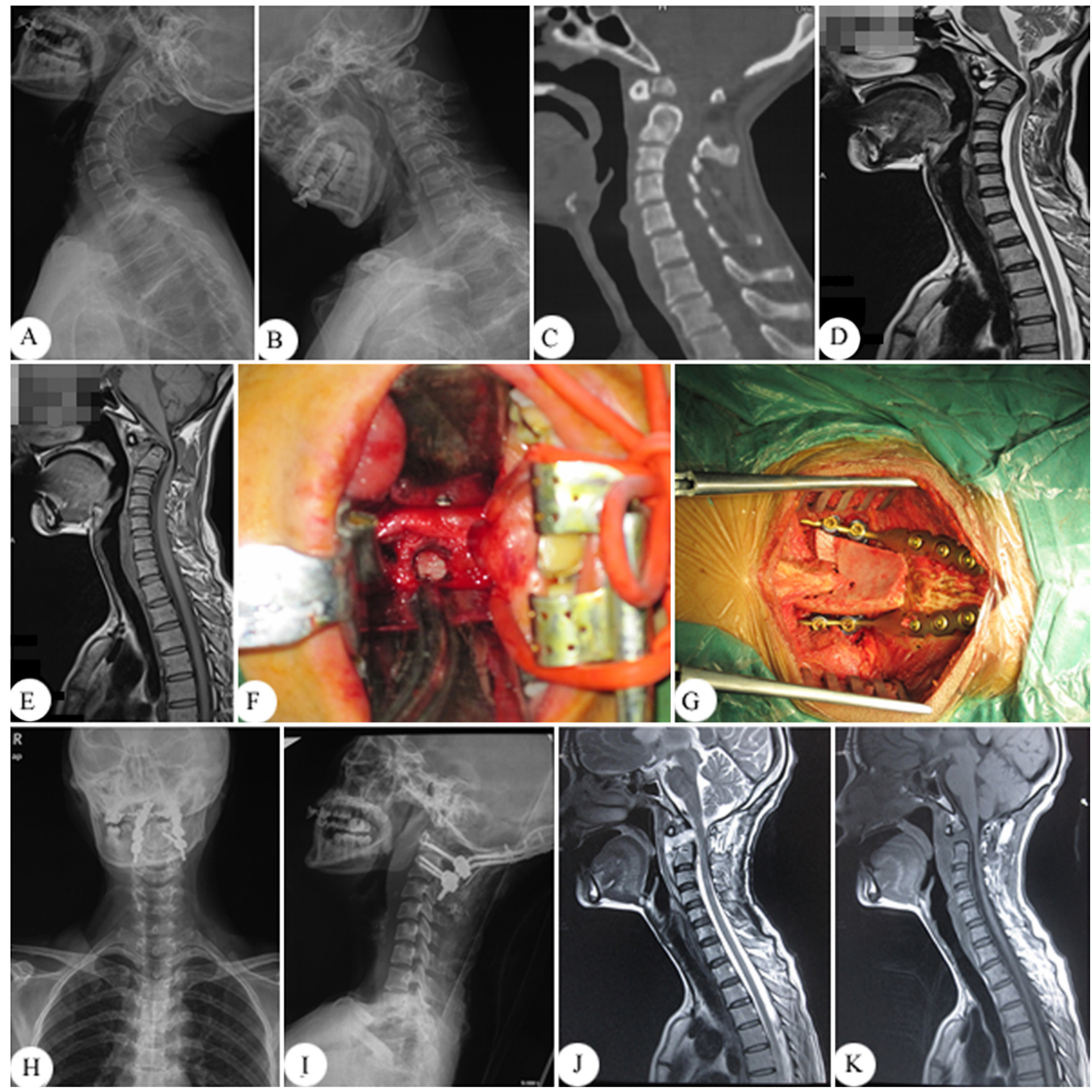

FIG. 3. A 46-year-old woman presented with os odontoideum with atlantoaxial dislocation. Preoperative extension (A) and flexion (B) cervical radiographs and a sagittal CT scan (C) show instability of the upper cervical spine with os odontoideum. Sagittal T2-weighted (D) and T1-weighted (E) MR images show a dystopic-type os odontoideum with ventral compression of the cervical spinal cord. Intraoperative photographs show the transoral approach for anterior decompression $(F)$ and occipitocervical fusion (G). Postoperative radiographs ( $\mathrm{H}$ and I) show the position of the hardware. Sagittal T2-weighted (J) and sagittal T1-weighted (K) MR images demonstrate sufficient decompression of the spinal cord. The patient could walk well after the operation. Figure is available in color online only.

radiographic instability. In normal situations, the structures around the odontoid process might be strong enough for activities of routine daily living. However, in some situations (e.g., os odontoideum), these structures fail to provide adequate stability, and injury to the spinal cord will thus occur eventually. Sudden death and serious neurological morbidity have been reported in patients with undiagnosed os odontoideum after minor trauma. 11,17,24

Zhang et al. ${ }^{33}$ presented 3 examples of patients with asymptomatic os odontoideum who later developed a spinal cord injury due to accidents. In addition, the authors concluded that surgical fusion and instrumentation should 


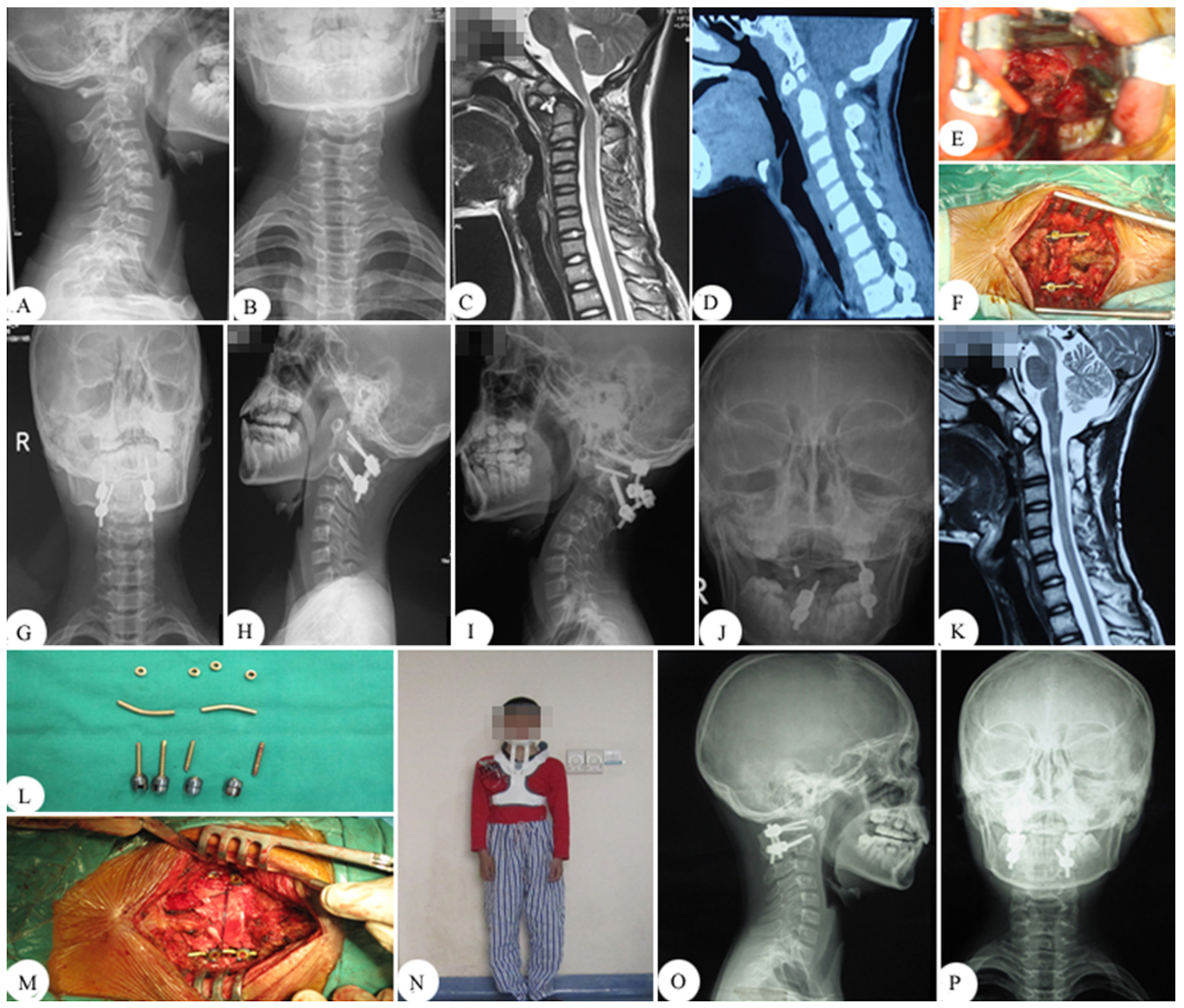

FIG. 4. A 12-year-old boy presented with os odontoideum and compression of the spinal cord. Lateral (A) and anteroposterior (B) cervical radiographs show a typical os odontoideum. A sagittal T2-weighted MR image (C) and a sagittal CT scan (D) show the patient with os odontoideum and spinal cord compression. Intraoperative photographs show the transoral approach for anterior decompression (E) and bilateral C-1 lateral mass screws and C-2 pedicle screws and iliac crest autograft (F). Postoperative anteroposterior $(\mathbf{G})$ and lateral $(\mathbf{H})$ radiographs show C1-2 instrumentation. Six-month postoperative lateral (I) and anteroposterior (J) radiographs show breakage of the pedicle screws. An MR image $(\mathbf{K})$ shows no ventral compression of the cervical spinal cord. Photographs obtained during the revision surgery show that bilateral C-1 lateral mass screws and C-2 pedicle screws (L) were placed with an iliac crest autograft $(\mathbf{M})$. A photograph $(\mathbf{N})$ was also obtained after the revision surgery. Three months postoperatively, the patient had no neurological deficits, and postoperative cervical lateral $(\mathbf{O})$ and anteroposterior $(\mathbf{P})$ radiographs indicated rigid internal fixation of $\mathrm{C} 1-2$. Figure is available in color online only.

be recommended in all patients with radiographically unstable os odontoideum, whether they were symptomatic or not. Other studies in the literature have reported that asymptomatic patients with os odontoideum are strongly advised to undergo surgery, especially those who are young, have anatomy favorable for surgical treatment, and have radiological evidence of atlantoaxial instability. ${ }^{10}$

Although symptomatic patients were involved in these studies, we believe that patients with radiographic instability should undergo surgery regardless of whether they have asymptomatic or symptomatic os odontoideum. Os odontoideum significantly influences the stability of the atlantoaxial joint, with the potential for severe spinal cord injury occurring by slight trauma. Therefore, accurate diagnosis and effective prevention and treatment in the early stages have important clinical significance. Posterior short-segment fixation and fusion is effective for patients without significant displacement of the atlantoaxial joint or with reducible atlantoaxial dislocation after traction. For patients with irreducible atlantoaxial dislocation or 
reducible atlantoaxial dislocation with remaining spinal cord compression due to paravertebral soft tissue, combined transoral decompression and posterior fusion and stabilization is recommended.

Since the first description of cervical pedicle screws in 1964, cervical pedicle screw fixation has been used to treat various types of pathological conditions, such as rheumatoid arthritis, cervical trauma, and bony abnormalities (e.g., os odontoideum), and they have become more popular for use in the cervical spine and are widely used in clinical practice. The safety of screw placement has also gained increasing attention.

Compared with lateral mass screws, cervical pedicle screws have the advantage of rigid 3D fixation without the need for supplemental external fixation. From a biomechanical perspective, cervical pedicle screws have a lower rate of loosening at the bone-screw interface and higher strength in fatigue testing compared with other fixation procedures. ${ }^{9,12}$ However, misplaced screws can induce a series of complications, such as nerve root injuries, VA injuries, or injuries to the dural sac or spinal cord.

Stabilization of the atlantoaxial complex is a unique and challenging procedure for surgeons because of the anatomical variability in both bony anatomy and VA course. For the posterior stabilization of os odontoideum with atlantoaxial instabilities, various techniques have been developed for instrumentation and stabilization at the $\mathrm{C} 1-2$ levels; among them, the $\mathrm{C} 1-2$ pedicle screw technique is a widely accepted standard method., $7,8,16,23,25$ Although this technique provides superior biomechanical stability and good fusion rates, it also has a high risk of VA injuries. The safe margin at $\mathrm{C} 1-2$ is narrow but sufficient if the pedicle screw is inserted under strict control. Otherwise, screw misplacement may occur, leading to catastrophic consequences such as injury to the VA, spinal cord, or nerve roots. $5,13,19,30,32$

Abumi et al. presented 3 patients with neurovascular complications that were directly due to cervical pedicle screw insertion. ${ }^{1}$ Madawi et al. reported 5 cases of VA injury and 1 case of temporary cranial nerve palsy among 61 patients who underwent $\mathrm{C} 1-2$ posterior screw fixation. ${ }^{15}$ The perforation rate of manual pedicle screw insertion has ranged from $2.3 \%$ to $21 \%$ in the cervical spine., ${ }^{1,12,18,21}$ In recent years, to achieve accurate placement of pedicle screws, computer navigation systems, CT cutout techniques, and specific navigation templates have been introduced into cervical spine surgery. ${ }^{14,18}$

According to our experiences, anteroposterior and lateral cervical radiographs are not sufficient to assist in the diagnosis and treatment of an os odontoideum. Instead, dynamic flexion and extension lateral radiographs should be obtained to analyze atlantoaxial stabilization. In addition, high-resolution 3D CT scanning and MRI should be done to provide the necessary detailed anatomy of the os odontoideum and spinal cord signal change at the related level. Preoperative CT assessment is important because it can help determine the VA course, bony anatomy, and trajectory for C1-2 screw placement. It is also important to analyze the preoperative imaging results, which can provide information regarding the normal and abnormal conditions of the cervical pedicles and surrounding tissues.
When performing pedicle screw instrumentation in the cervical spine, surgeons must keep in mind the anatomical variations of the pedicle and the VA. CT scans are useful in assessing the regional vascular anatomy in a patient with os odontoideum, especially for the presence of an anomalous VA. ${ }^{28,29}$ In our study, the preoperative CT scans showed an anomalous VA at the C-2 level; therefore, we chose to perform transpedicular screw fixation at C-1 and C-3, which avoided a possible catastrophic vascular event.

The structure of the atlantoaxial vertebral complex (C1-2) is unique, with no intervertebral disc between the intervertebral bodies (that is, ligaments and joint capsules only). C1-2 is the largest rotary motion unit in the cervical spine, accounting for more than half of the entire cervical spine rotation. The point has been argued whether C1-2 fusion can significantly influence neck rotation and daily activities of patients with os odontoideum. Although the procedure could induce the loss of normal neck rotation by as much as $50 \%$, the remaining joints could compensate for most of the function of $\mathrm{C} 1-2$. Compared with the potentially catastrophic cord compression that can occur, the side effects associated with this procedure are a small price to pay for the spinal stability.

In the case of 1 patient in our series, occipitocervical instability existed after transoral anterior decompression. Thus, transpedicular C1-2 screw fixation and fusion were not suitable for the patient, and we instead chose occipitocervical fusion. In addition, although different types of artificial bone exist, bone typically taken from the patient's posterior iliac crest remains the gold standard. In this study, an iliac crest autograft was harvested and secured between $\mathrm{C}-1$ and $\mathrm{C}-2$. Posterior fixation and fusion immediately provide stabilization in the operative segment and create an environment suitable for bone union.

The current study has 3 limitations. The first limitation is that it is a retrospective study, which might have caused technical selection bias and clinical observation bias. The second is that there was no control for each surgical technique. The third limitation is surgeon bias, because all surgeries were performed by the same surgeon. Most surgeons are familiar with posterior surgery; however, the technique of transoral decompression is not routinely mastered by surgeons. In addition, complications of the transoral procedure also influence the surgeon's choice.

The treatment principles for os odontoideum were proposed by the American Association of Neurological Surgeons and the Congress of Neurological Surgeons in 2001 as follows. In symptomatic patients and in those with C1-2 instability, posterior fixation and fusion were suggested, such as $\mathrm{C} 1-2$ pedicle screw fixation and fusion or occipitocervical fusion and fixation. For patients with an irreducible dislocation, transoral decompression was suggested. Therefore, although the surgeries should be (and for the most part are) performed as the guidelines dictate, surgeon preference does play a part.

However, the current study has 2 advantages: 1) All surgeries were performed by the same surgeon, thus eliminating any potential for errors produced by differences in surgical technique; and 2) all patients had regular follow-up, and complete pre- and postoperative clinical and imaging data were obtained. In future research, a prospective study 
to compare the techniques for the treatment of os odontoideum will be conducted, and the treatment for irreducible dislocation might be successful by another method that does not involve transoral operation.

\section{Conclusions}

Preoperative skull traction is very important for the treatment of os odontoideum, and obtaining dynamic radiographs during the process will aid in selection of the optimal operative procedure. According to our experiences, symptomatic patients with C1-2 instability should be treated by posterior stabilization, such as transpedicular C1-2 screw fixation or occipitocervical fusion. Transoral decompression is suggested in patients with os odontoideum and irreducible atlantoaxial dislocation. Pedicle screw fixation and autologous bone fusion can be used to provide immediate stabilization, and spinal cord decompression is usually necessary to relieve neurological symptoms. Once C1-2 fusion has been achieved, patients will obtain permanent stability of the upper cervical spine, and they will survive catastrophic spinal cord injury from $\mathrm{C1}-2$ translation.

\section{Acknowledgments}

This study was supported by grants from the National Science Foundation of China (grants 81201393 and 2013YGYL015).

\section{References}

1. Abumi K, Shono Y, Ito M, Taneichi H, Kotani Y, Kaneda $\mathrm{K}$ : Complications of pedicle screw fixation in reconstructive surgery of the cervical spine. Spine (Phila Pa 1976) 25:962969,2000

2. Acosta FL Jr, Quinones-Hinojosa A, Gadkary CA, Schmidt $\mathrm{MH}$, Chin CT, Ames CP, et al: Frameless stereotactic imageguided C1-C2 transarticular screw fixation for atlantoaxial instability: review of 20 patients. J Spinal Disord Tech 18:385-391, 2005

3. Ai F, Yin Q, Wang Z, Xia H, Chang Y, Wu Z, et al: Applied anatomy of transoral atlantoaxial reduction plate internal fixation. Spine (Phila Pa 1976) 31:128-132, 2006

4. Arvin B, Fournier-Gosselin MP, Fehlings MG: Os odontoideum: etiology and surgical management. Neurosurgery 66 (3 Suppl):22-31, 2010

5. Bransford RJ, Lee MJ, Reis A: Posterior fixation of the upper cervical spine: contemporary techniques. J Am Acad Orthop Surg 19:63-71, 2011

6. Ford FR: Syncope, vertigo and disturbances of vision resulting from intermittent obstruction of the vertebral arteries due to defect in the odontoid process and excessive mobility of the second cervical vertebra. Bull Johns Hopkins Hosp 91:168-173, 1952

7. Goel A: Techniques of posterior $\mathrm{C} 1-\mathrm{C} 2$ stabilization. Neurosurgery 62:E1384, 2008 (Letter)

8. Harms J, Melcher RP: Posterior C1-C2 fusion with polyaxial screw and rod fixation. Spine (Phila Pa 1976) 26:2467-2471, 2001

9. Johnston TL, Karaikovic EE, Lautenschlager EP, Marcu D: Cervical pedicle screws vs. lateral mass screws: uniplanar fatigue analysis and residual pullout strengths. Spine J 6:667-672, 2006

10. Klimo P Jr, Coon V, Brockmeyer D: Incidental os odontoideum: current management strategies. Neurosurg Focus 31(6):E10, 2011

11. Klimo P Jr, Kan P, Rao G, Apfelbaum R, Brockmeyer D: Os odontoideum: presentation, diagnosis, and treatment in a series of 78 patients. J Neurosurg Spine 9:332-342, 2008

12. Kotani Y, Abumi K, Ito M, Minami A: Improved accuracy of computer-assisted cervical pedicle screw insertion. J Neurosurg 99 (3 Suppl):257-263, 2003

13. Lowry DW, Pollack IF, Clyde B, Albright AL, Adelson PD: Upper cervical spine fusion in the pediatric population. $\mathbf{J}$ Neurosurg 87:671-676, 1997

14. Lu S, Xu YQ, Lu WW, Ni GX, Li YB, Shi JH, et al: A novel patient-specific navigational template for cervical pedicle screw placement. Spine (Phila Pa 1976) 34:E959-E966, 2009

15. Madawi AA, Casey AT, Solanki GA, Tuite G, Veres R, Crockard HA: Radiological and anatomical evaluation of the atlantoaxial transarticular screw fixation technique. J Neurosurg 86:961-968, 1997

16. Menendez JA, Wright NM: Techniques of posterior C1-C2 stabilization. Neurosurgery 60 (1 Supp1 1):S103-S111, 2007

17. Minderhoud JM, Braakman R, Penning L: Os odontoideum, clinical, radiological and therapeutic aspects. J Neurol Sci 8:521-544, 1969

18. Miyamoto H, Uno K: Cervical pedicle screw insertion using a computed tomography cutout technique. J Neurosurg Spine 11:681-687, 2009

19. Parker SL, McGirt MJ, Garcés-Ambrossi GL, Mehta VA, Sciubba DM, Witham TF, et al: Translaminar versus pedicle screw fixation of $\mathrm{C} 2$ : comparison of surgical morbidity and accuracy of 313 consecutive screws. Neurosurgery 64 (5 Suppl 2):343-349, 2009

20. Qureshi MA, Afzal W, Malik AS, Ullah JS, Aebi M: Osodontoideum leading to atlanto-axial instability-report of surgery in four cases. J Pak Med Assoc 58:640-642, 2008

21. Richter M, Cakir B, Schmidt R: Cervical pedicle screws: conventional versus computer-assisted placement of cannulated screws. Spine (Phila Pa 1976) 30:2280-2287, 2005

22. Salunke P, Behari S, Kirankumar MV, Sharma MS, Jaiswal AK, Jain VK: Pediatric congenital atlantoaxial dislocation: differences between the irreducible and reducible varieties. J Neurosurg 104 (2 Suppl):115-122, 2006

23. Smith MD, Phillips WA, Hensinger RN: Fusion of the upper cervical spine in children and adolescents. An analysis of 17 patients. Spine (Phila Pa 1976) 16:695-701, 1991

24. Stevens JM, Chong WK, Barber C, Kendall BE, Crockard HA: A new appraisal of abnormalities of the odontoid process associated with atlanto-axial subluxation and neurological disability. Brain 117:133-148, 1994

25. Stokes JK, Villavicencio AT, Liu PC, Bray RS, Johnson JP: Posterior atlantoaxial stabilization: new alternative to C1-2 transarticular screws. Neurosurg Focus 12(1):E6, 2002

26. Stulik J, Vyskocil T, Sebesta P, Kryl J: Atlantoaxial fixation using the polyaxial screw-rod system. Eur Spine J 16:479484, 2007

27. Xu J, Yin Q, Xia H, Wu Z, Ma X, Zhang K, et al: New clinical classification system for atlantoaxial dislocation. Orthopedics 36:e95-e100, 2013

28. Yamazaki M, Koda M, Aramomi MA, Hashimoto M, Masaki Y, Okawa A: Anomalous vertebral artery at the extraosseous and intraosseous regions of the craniovertebral junction: analysis by three-dimensional computed tomography angiography. Spine (Phila Pa 1976) 30:2452-2457, 2005

29. Yamazaki M, Koda M, Yoneda M, Aiba A, Moriya H: Anomalous vertebral artery at the craniovertebral junction in a patient with Down syndrome. Case report. J Neurosurg Spine 1:338-341, 2004

30. Yeom JS, Buchowski JM, Park KW, Chang BS, Lee CK, Riew KD: Undetected vertebral artery groove and foramen violations during $\mathrm{C} 1$ lateral mass and $\mathrm{C} 2$ pedicle screw placement. Spine (Phila Pa 1976) 33:E942-E949, 2008

31. Yin Q, Ai F, Zhang K, Chang Y, Xia H, Wu Z, et al: Irreduc- 
ible anterior atlantoaxial dislocation: one-stage treatment with a transoral atlantoaxial reduction plate fixation and fusion. Report of 5 cases and review of the literature. Spine (Phila Pa 1976) 30:E375-E381, 2005

32. Yoshida M, Neo M, Fujibayashi S, Nakamura T: Comparison of the anatomical risk for vertebral artery injury associated with the C2-pedicle screw and atlantoaxial transarticular screw. Spine (Phila Pa 1976) 31:E513-E517, 2006

33. Zhang Z, Wang H, Liu C: Acute traumatic cervical cord injury in pediatric patients with os odontoideum: a series of 6 patients. World Neurosurg 83:1180.e1-1180.e6, 2015

\section{Disclosures}

The authors report no conflict of interest concerning the materi- als or methods used in this study or the findings specified in this paper.

\section{Author Contributions}

Conception and design: Ge, Shao. Acquisition of data: $\mathrm{Wu}$, Gao, Li, Ge. Analysis and interpretation of data: Gao. Drafting the article: Wu. Critically revising the article: Wood. Statistical analysis: Wood, Li, Zhao. Administrative/technical/material support: C Yang, Wang, S Yang. Study supervision: Wang, Shao.

\section{Correspondence}

Cao Yang, Department of Orthopaedics, Union Hospital, Tongji Medical College, Huazhong University of Science and Technology, Wuhan 430022, China. email: yangcaom@gmail. com 